\title{
Hereditary Corneal Dystrophy
}

National Cancer Institute

\section{Source}

National Cancer Institute. Hereditary Corneal Dystrophy. NCI Thesaurus. Code C34512.

A family of inherited disorders characterized by the gradual, prog ressive accumulation of extraneous material on one or both corneas, which, without proper treatment, can impair vision. 